\title{
Hippocampal Pyramidal Cell-Interneuron Spike Transmission Is Frequency Dependent and Responsible for Place Modulation of Interneuron Discharge
}

\author{
Lisa Marshall, Darrell A. Henze, Hajime Hirase, Xavier Leinekugel, George Dragoi, and György Buzsáki \\ Center for Molecular and Behavioral Neuroscience, Rutgers, The State University of New Jersey, Newark, \\ New Jersey 07102
}

The interplay between principal cells and interneurons plays an important role in timing the activity of individual cells. We investigated the influence of single hippocampal CA1 pyramidal cells on putative interneurons. The activity of CA1 pyramidal cells was controlled intracellularly by current injection, and the activity of neighboring interneurons was recorded extracellularly in the urethane-anesthetized rat. Spike transmission probability between monosynaptically connected pyramidal cell- interneuron pairs was frequency dependent and highest between 5 and $25 \mathrm{~Hz}$. In the awake animal, interneurons were found that had place-modulated firing rates, with place maps similar to their presynaptic pyramidal neuron. Thus, single pyramidal neurons can effectively determine the firing patterns of their interneuron targets.

Key words: hippocampus; spike transmission; interneuron; depression; place cells; temporal coding
Hippocampal interneurons are suggested to play an essential role in timing the occurrence of pyramidal cell activity by imposing a coordinated oscillatory "context" for the "content" carried by networks of principal cells (Buzsáki and Chrobak, 1995; Cobb et al., 1995; Whittington et al., 1995; Freund and Buzsáki, 1996; Geiger et al., 1997; Fricker and Miles, 2000). In addition to such a global role, interneurons may play a critical role in sculpting the activity of their local network. A single interneuron is estimated to contact several hundred pyramidal cells (Sik et al., 1995). In the opposite direction, interneurons are under the control of both local and distal afferent excitation, but the relative impact of the various inputs to interneurons is less investigated. Both in vitro and in vivo studies suggest that the pyramidal cell-interneuron synapse is particularly efficient (Miles 1990; Gulyas et al., 1993; Csicsvari et al., 1998; Cohen and Miles, 2000). Recently, extracellular recordings in behaving rats revealed a high spike transmission probability between pyramidal cells and putative basket cells in the CA1 pyramidal layer, using a cross-correlation analysis. These observations suggested that even a single CA1 pyramidal cell can exert an impact on network activity by way of its target interneurons. However, in the study of Csicsvari et al. (1998), it could not be ruled out that some unrecorded presynaptic pyramidal cells also contributed to the short-latency discharge of the recorded postsynaptic interneuron. Therefore, in the present study we investigated the probability of spike transmission in pyramidal cell-interneuron pairs by controlling spike occurrence of pyramidal neurons with intracellular current injection. After finding that an individual CA1 pyramidal cell can

\footnotetext{
Received July 10, 2001; revised Oct. 12, 2001; accepted Oct. 16, 2001.

This work was supported by the Deutsche Forschungsgemeinschaft (LM/ 2053/2) and National Institutes of Health (54671; 34994; P41-RR09754; 2403). We thank E. Borok for her skillful technical assistance.

Correspondence should be addressed to György Buzsáki, Center for Molecular and Behavioral Neuroscience, Rutgers University, 197 University Avenue, Newark, NJ 07102. E-mail: buzsaki@axon.rutgers.edu.

L. Marshall's present address: Medical University Lübeck, Clinical Research Group, H23a Ratzeburger Allee 160, 23538, Lübeck, Germany.

Copyright (C) 2002 Society for Neuroscience $\quad 0270-6474 / 02 / 220001-\bullet \$ 15.00 / 0$
}

monosynaptically discharge a neighboring interneuron, we addressed the issue of whether behavioral correlates of the pyramidal cell (O'Keefe and Nadel, 1978) are also reflected in the firing patterns of its postsynaptic interneuron.

\section{MATERIALS AND METHODS}

Acute experiments. Forty-five male rats $(350-450 \mathrm{gm})$ of the strain Sprague Dawley were anesthetized with urethane $(1.5 \mathrm{gm} / \mathrm{kg})$ and placed in a stereotaxic apparatus for surgery and recording. Constant body temperature was maintained by an animal heat pad. Paired extracellular and intracellular recordings were obtained by the procedure described by Henze et al. (2000). In brief, extracellular and intracellular electrodes were mounted on manipulators of a stereotaxic apparatus (Kopf Instruments, Tujunga, CA). The manipulator of the extracellular tetrode (Gray et al., 1995) was mounted at a $10^{\circ}$ angle from the vertical plane (Henze et al., 2000). Guided by unit activity and evoked field potentials, the extracellular electrode was lowered into the CA1 region of the hippocampus until a putative interneuron was recorded in or close to stratum pyramidale. On-line criteria for determining the occurrence of an interneuron unit were the duration of the extracellular spikes $(<0.8 \mathrm{msec})$, wave shape, and firing rate (Csicsvari et al., 1998). For the off-line isolation of interneuron spikes, a semi-automatic clustering procedure was used (Harris et al., 2000). Once stable extracellular recording was obtained, an intracellular sharp pipette, containing a $1 \mathrm{M}$ potassium acetate solution, was lowered into the pyramidal layer $<100 \mu \mathrm{m}$ from the recorded interneuron. After the microelectrode was lowered, the skull hole was filled with a paraffin mixture.

Intracellular signals were recorded using an Axoclamp-2A (Axon Instruments, Foster City, CA) under conditions of spontaneous activity

This article is published in The Journal of Neuroscience, Rapid Communications Section, which publishes brief, peerreviewed papers online, not in print. Rapid Communications are posted online approximately one month earlier than they would appear if printed. They are listed in the Table of Contents of the next open issue of JNeurosci. Cite this article as: JNeurosci, 2002, 22:RC197 (1-5). The publication date is the date of posting online at www.jneurosci.org.

http://www.jneurosci.org/cgi/content/full/5971 
Figure 1. Schematized recording procedure. $A$, A tetrode for extracellular recording was inserted into the CA1 pyramidal cell layer at an angle to record putative interneuron(s). A sharp glass micropipette impaled a pyramidal cell $<100$ $\mu \mathrm{m}$ from the interneuron. The intracellularly recorded pyramidal cell was later revealed by biocytin staining $(A)$. $B$, Superimposed traces of the activity of a putative interneuron (int; $800 \mathrm{~Hz}-3 \mathrm{kHz}$ ) and intracellularly recorded pyramidal cell. Insets, Spike distribution of the interneuron at high temporal resolution $(0.1 \mathrm{msec})$. Note short-latency ( $<2 \mathrm{msec})$ discharge of the interneuron by the presynaptic pyramidal cell. $C$, Cross-correlation between the pyramidal cell spikes (reference event) and interneuron spikes. Spikes from the two cells were shuffled, and the shuffled values were subtracted from the original histograms. Dotted lines indicate 3 SDs of the mean $(p<0.002)$. Note similar spike transmission probability for spikes that occurred spontaneously in the pyramidal cell or were evoked by intracellular current injection. $D$, Dependence of spike transmission on the frequency of the presynaptic pyramidal cell spikes. $\bigcirc$, Spontaneously occurring spikes; - , spikes induced by short current steps (4 msec) at various frequencies. Spike transmission probability was calculated for all presynaptic spikes in the evoked trains, excluding the first spike. Note the highest spike transmission probability at $10 \mathrm{~Hz}$.

or by intracellular current injection. Current injection occurred either as long depolarizing pulses of $40-500 \mathrm{msec}$ duration $(0.2-1.2 \mathrm{nA})$ or as a train of 10 short 4 msec steps. Monosynaptic pyramidal-interneuron pair connections could be observed on-line by superimposition of extracellular putative interneuron unit activity time-locked to the intracellular action potential (see Fig. $1 B$ ). The putative connection was verified by a significant cross-correlation between the peak time of the pyramidal cell action potential and negative peak of the unit activity of the putative interneuron. Cross-correlation histograms were expressed as probability by dividing each bin by the number of reference events (i.e., the occurrence of pyramidal cell spikes). A second, shuffled cross-correlation histogram calculated by shifting the spike train of the putative interneuron discharge times was subtracted from the original to reduce the effect of random interactions. Bin values above 3 SDs from the baseline of the derived histograms were regarded as significant $(p=0.0013$; assuming normal distribution). Probability of spike transmission was estimated as the maximum count within 1-3 msec of the corrected cross-correlogram (Csicsvari et al., 1998). When trains of spikes were evoked by short current steps at defined frequencies, spike transmission probability was calculated for all presynaptic spikes in the evoked trains after excluding the first spike. For long current steps, spike transmission probability was calculated separately for each spike position to assess an effect on spike order.

Chronic studies. Twelve male rats of the Long-Evans strain (300-500 gm) were implanted with eight individually movable tetrodes. The tetrodes were inserted into the CA1 pyramidal layer with $300 \mu \mathrm{m}$ center spacings. The rats were tested either in a running wheel task (Czurkó et al., 1999) or in a large rectangular plywood box $(1.2 \times 1.2 \times 0.5 \mathrm{~m} \mathrm{high})$ with various objects (Hirase et al., 2001a). An infrared light-emitting diode was attached to the head stage to track the position of the animal (Czurkó et al., 1999). After amplification $(10,000 \times)$ and band-pass filtering $(1 \mathrm{~Hz}-5 \mathrm{kHz})$, field potentials and extracellular action potentials were digitized continuously at $20 \mathrm{kHz}$ rate with a DataMax system (16 bit resolution; RC Electronics, Santa Barbara, CA). Interneurons and pyramidal cells were separated by a semi-automatic clustering procedure (Harris et al., 2000). Monosynaptic connections between pyramidal cellinterneuron pairs were quantified as described above. After completion of the experiments the rats were deeply anesthetized and perfused. The brains were sectioned and stained with the cresyl violet method to verify electrode placements.

\section{RESULTS}

\section{A single CA1 pyramidal cell can reliably drive its target interneuron}

By appropriate positioning of the extracellular and intracellular recording electrodes in the CA1 pyramidal layer, monosynaptically connected pyramidal cell-interneuron pairs could be identified. Previous experiments indicated that the probability of such pairs is much higher within a radius of $150 \mu \mathrm{m}$ than at longer distances (Csicsvari et al., 1998; Cohen and Miles, 2000). In 26 of
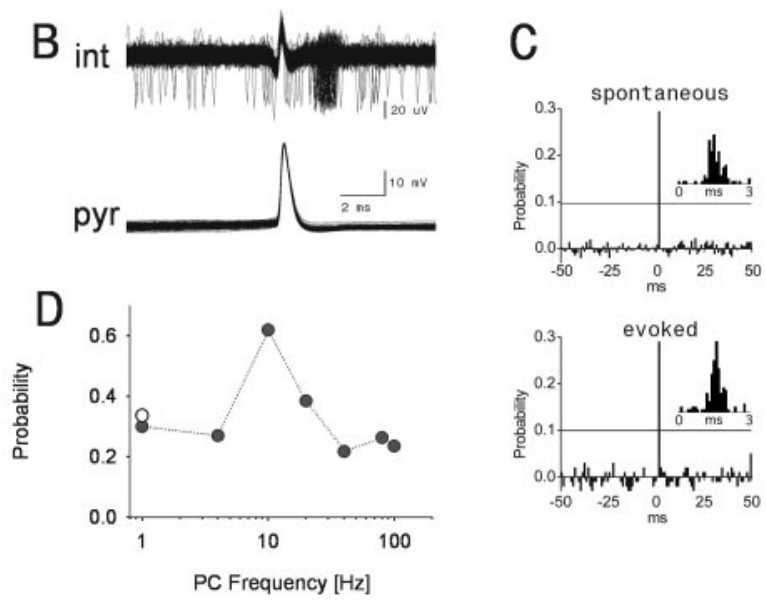

45 experiments the intracellular and extracellular electrodes were positioned $<150 \mu \mathrm{m}$. In a portion of these experiments $(n=12)$, an interneuron was recorded by the extracellular electrode (Fig. $1 A$ ), in addition to other pyramidal cells. Once the presence of the interneuron was established, repeated attempts were made to impale a presynaptic pyramidal cell. Current- or injury-induced discharge of the pyramidal cell often drove the interneuron within $<3$ msec. When several pyramidal cells were impaled in succession, typically only one or none could drive the interneuron, indicating that only a portion of the nearby pyramidal cells innervated the same interneuron. In four experiments, pyramidal cell-interneuron pairs were recorded for $>30 \mathrm{~min}$ and with clearly separable interneuron spikes (see Materials and Methods). These recordings provided a sufficient number of action potentials to quantitatively evaluate spike transmission probability from the presynaptic pyramidal cell to the postsynaptic interneuron in several conditions (Fig. 1). Spike transmission probabilities ranged between 0.02 and $0.4(0.18 \pm 0.03$; mean $\pm \mathrm{SE})$ and were similar for spontaneously occurring and current stepevoked spikes (Fig. 1C). The mean latency between the peaks of the intracellular action potential and the extracellular interneuron spike was $1.54 \mathrm{msec}( \pm 0.82 \mathrm{msec})$.

The anatomical identity of the monosynaptically driven neurons could not be revealed with extracellular recordings. It is known, however, that interneurons with cell bodies in the pyramidal layer correspond to basket cells, chandelier cells, and bistratified interneurons (Freund and Buzsáki, 1996). In vitro experiments indicated that the pyramidal cell synapses on these interneurons show paired-pulse depression (Ali et al., 1998). Therefore, we investigated the short-term use-dependent effects on spike transmission probability. In the first test, bursts of spikes were evoked in the pyramidal cell by long depolarizing pulses of 40-500 msec duration (Fig. 2A,B). The pyramidal cell responded to these prolonged steps with a train of accommodating spikes, with the largest depression of spike transmission probability between the first and second spike (Fig. 2C,D). This suggested that either the high frequency of the spikes (mean interval, $10.5 \pm 2.22$ $\mathrm{msec}$ ) or something more general about the second spike was responsible for the depression. Therefore, we examined spike transmission probability specifically as a function of the frequency of the presynaptic spikes ( $n=2$ pairs). In this test, action potentials were evoked by trains of 10 step pulses of $4 \mathrm{msec}$ (one 

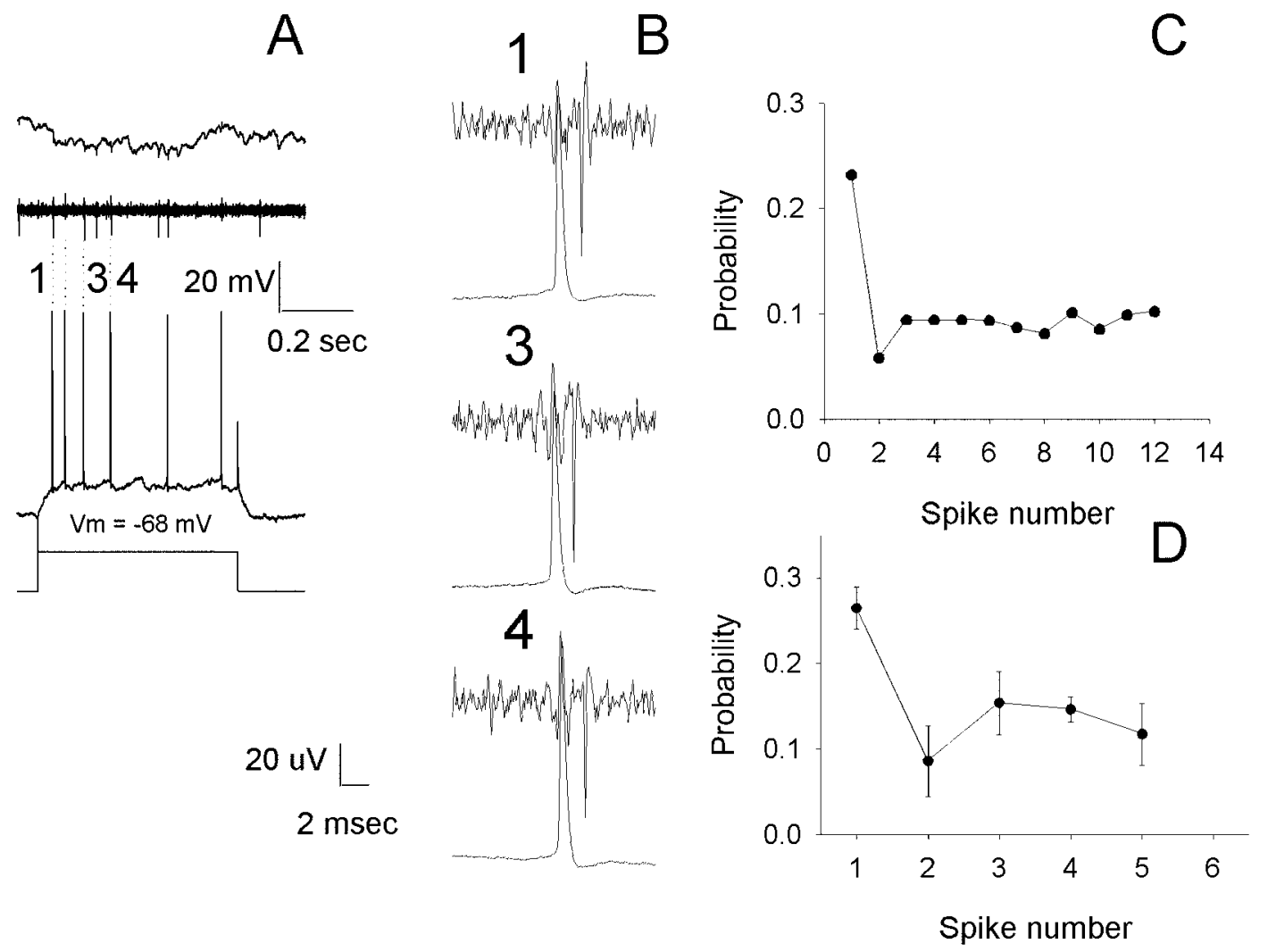

Figure 2. Suppression of monosynaptic pyramidal-interneuron spike transmission probability. $A$, Relationship between long current step-induced action potentials in the pyramidal cell and interneuron spikes. Wide band $(1 \mathrm{~Hz}-3 \mathrm{kHz})$ and bandpass-filtered traces of the extracellular traces are shown. Interneuron spikes occurred $<2 \mathrm{msec}$ after the first, third, and fourth pyramidal cell spikes, shown in detail in $B$. $C$, Changes in spike transmission probability from the 1st to 12th spike position for the neuron pair shown in $A$ and $B$. Spike transmission probability was calculated separately for the 1 st through 12 th presynaptic spike. $D$, Average of three neuron pairs. The mean instantaneous firing frequency of the second spike ranged between 80 and $120 \mathrm{~Hz}$ for the different pyramidal cells and was lower for subsequent spikes.

spike per step) at various frequencies. In both neuron pairs tested, we found that the highest probability of spike transmission occurred between 5 and $25 \mathrm{~Hz}$, with relatively low probabilities above $40 \mathrm{~Hz}$ or below $3 \mathrm{~Hz}$ (Fig. 1D). These findings indicated that the firing patterns of the presynaptic pyramidal cell can affect the efficacy of synaptic transmission between the pyramidal cell and interneuron.

\section{"Place" correlates of interneurons are secondary to pyramidal cell activity}

Previous studies have shown that in addition to pyramidal cells, interneurons can also display a reliable spatial distribution of their spikes. However, in contrast to pyramidal cells (place cells), the place fields of interneurons are typically large, sometimes with multiple centers (McNaughton et al., 1983; Kubie et al., 1990). In agreement with these previous reports, we found a significant place-related increase of firing rates in 12 of 26 CA1 interneurons. The field sizes represented by interneurons were several times larger than those of the pyramidal cells. Because of the high spike transmission probability between some pyramidal cell-interneuron pairs and the behavior dependence of the efficacy of the synaptic transmission (Csicsvari et al., 1998), we hypothesized that place correlates of interneurons are brought about by the activity of their presynaptic place cells. Three of the 12 interneurons with place correlates were postsynaptic to a simultaneously recorded place cell. An example is shown in Figure 3. In this experiment two pyramidal cells, recorded from the same tetrode, had adjacent place correlates $(P 1, P 2)$. One of the place cells was monosynaptically connected to a simultaneously recorded interneuron, as shown by the sharp shortlatency $(<3 \mathrm{msec})$ peak in the cross-correlograms (Fig. $3 A)$. Although the interneuron had multiple place fields, one of its place correlates was identical with the place field of its presynaptic pyramidal cell (Fig. $3 B$ ). The spatial extent of the field represented by the interneuron was somewhat larger than that of its presynaptic place cell. However, the peak firing of the interneuron and pyramidal cell coincided. Spatial overlap of the peak firing of monosynaptically connected place cell-interneuron pairs was similar in the remaining two cases in which interneurons possessed place correlates.

\section{DISCUSSION}

The present study examined the impact of presynaptic activity of CA1 pyramidal cells on their postsynaptic interneuron targets. We found that a single presynaptic pyramidal cell alone can discharge a putative postsynaptic interneuron. The high spike transmission probability between pyramidal cell-interneuron pairs was expressed at the behavioral level by the similar placerelated firing of the interneuron and the presynaptic pyramidal cell.

Our findings confirm and extend previous in vitro studies demonstrating the high reliability of synaptic transmission between principal cells and interneurons (Gulyas et al., 1993; Geiger et al., 


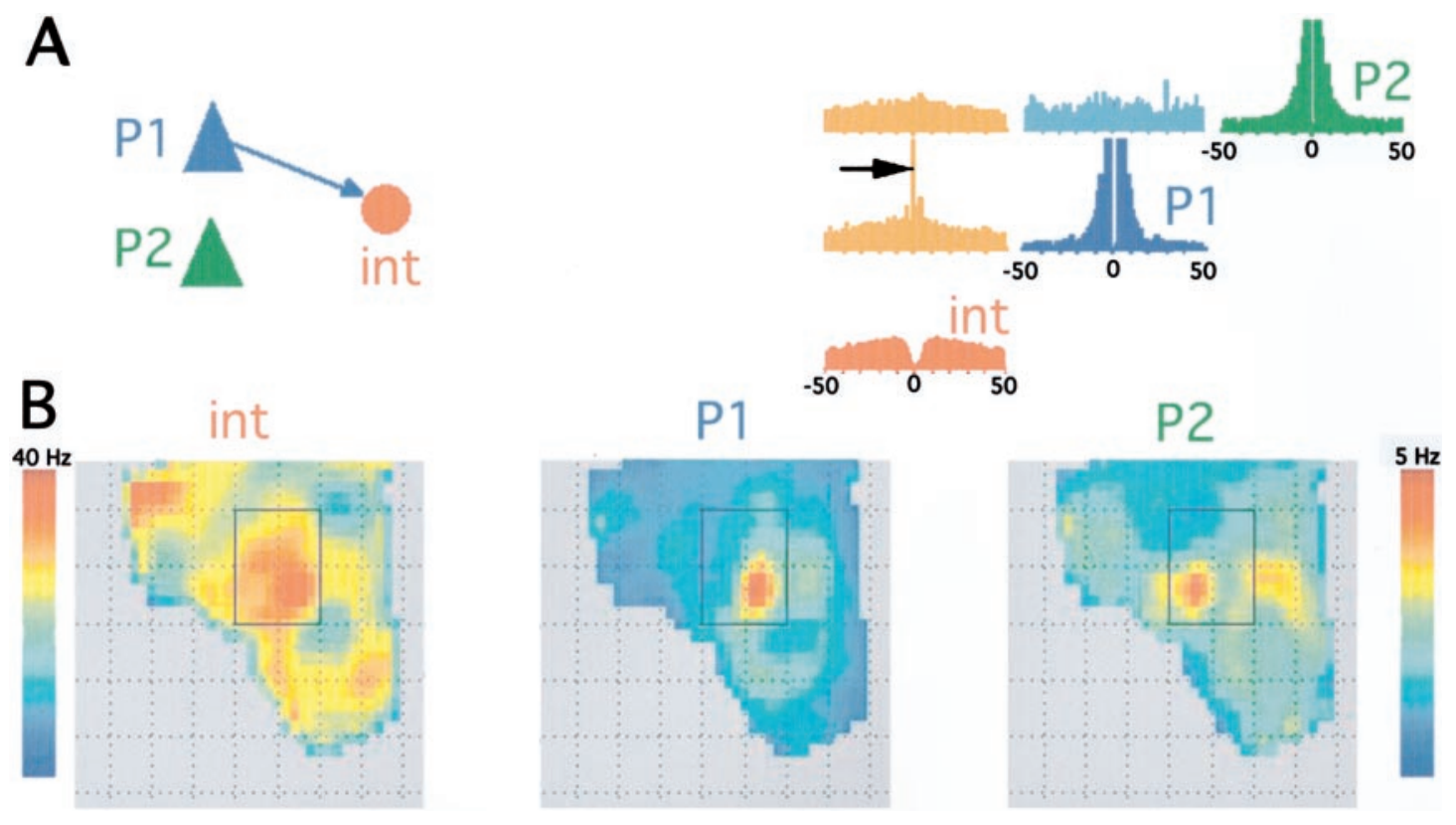

Figure 3. Spatial correlates of interneurons are attributable to their monosynaptic activation by presynaptic place cells. $A$, Autocorrelograms of two neighboring place cells ( $P 1$ and $P 2$; blue and green, respectively) and an interneuron (int; red) and their respective cross-correlograms (orange, light blue). The large peak at $-2 \mathrm{msec}$ (arrow) indicates monosynaptic connection between P1 and the interneuron. $B$, Color-coded firing rate place maps of the three neurons shown in $A$ in a larger square box. The rectangular box is added to highlight the place fields of $P 1$ and $P 2$. Note similar spatial discharge of the interneuron and its presynaptic pyramidal cell (P1; i.e., right, bottom corner of rectangle).

1997; Ali et al., 1998; Fricker and Miles, 2000; Galarreta and Hestrin, 2001). Although principal cells contact basket cells and other interneurons typically by a single release site, transmission failures are rare (Gulyas et al., 1993). In the awake rat, presynaptic spikes in pyramidal cells often resulted in a monosynaptic discharge of target interneurons (Csicsvari et al., 1998). However, in that study the contribution of other simultaneously active cells could not be excluded. In the present study, intracellular stimulation of a single pyramidal cell reliably discharged the target interneuron. The discharge probability of the postsynaptic neuron in response to spontaneously occurring presynaptic spikes and current-induced spikes was comparable. In addition, the postsynaptic spikes showed very little time jitter. Therefore, these findings conclusively demonstrate that single pyramidal cells can discharge postsynaptic interneurons with high reliability in the intact brain. It should be noted here that the spike transmission probability method may underestimate the number of pyramidalinterneuron connections because pairs with low spike transmission probabilities would be classified as nonconnected. Thus, the variability of spike transmission from pyramidal to interneurons can be quite large.

The identity of our extracellularly recorded interneurons remains to be elucidated. Because the recorded cell bodies were encountered in the pyramidal cell layer, they may represent basket cells, chandelier cells, or a subgroup of bistratified interneurons (Freund and Buzsaki, 1996). Glutamatergic synapses onto neurons in these classes have been shown to display usedependent modulation. We also observed a robust depression in spike transmission mainly from the first to the second presynaptic spike, similar to recordings from pyramidal cell-interneuron pairs in the slice preparation (Ali et al., 1998). The observation that higher frequencies $(>25 \mathrm{~Hz})$ of presynaptic activity are not as efficient as lower frequencies at driving interneurons is likely to be the reason for the robust depression of spike transmission from the first to the second spikes in a step-induced burst. The depression of spike transmission at higher frequencies is consistent with previous in vitro studies examining synaptic transmission (Thomson and Bannister, 1999; Waldeck et al., 2000). However, additional factors may also be involved (Manor et al., 1997; Borst and Sakmann, 1999; Frerking et al., 2001) because the efficacy of pyramidal cell-interneuron spike transmission was highest in the 5-25 Hz range and decreased again at lower frequencies. Thus, spike transmission is not a simple function of interspike interval, but each synapse may have some preferred frequency range [frequency filtering (Markram et al., 1998)].

The frequency tunability of the pyramidal cell-interneuron synapse may be an efficient mechanism to temporarily redistribute communication in active neuronal ensembles (Abbott et al., 1997; Tsodyks et al., 2000). In the hippocampus, such active groups may correspond to place cell assemblies (Wilson and McNaughton, 1993). The frequency of place cells corresponds to the range in which the pyramidal cell-interneuron spike transmission probability was highest $(5-25 \mathrm{~Hz})$. Thus, an active place cell can enhance its access to its target interneurons through frequency-tuned synapses, compared with other presynaptic pyramidal cells that discharge at a low frequency. This hypothesis can help explain the previous (McNaughton et al., 1983; Kubie et al., 1990) and present observations that the firing rates of several interneurons were not distributed homogenously over the visited places. Our finding that the peak firing rates of some interneurons coincided with the place field of the presynaptic pyramidal cell provides support for such a mechanism. Although hundreds of pyramidal cells are presynaptic to a single interneuron, only a small portion is active at any one time (Harris et al., 2000). Furthermore, place cells, representing the same part of the environment, are not clustered but are randomly distributed in the CA1 pyramidal layer (Redish et al., 2001). Importantly, most presynaptic partners of interneurons are local (Csicsvari et al., 
1998; Hirase et al., 2001b). Therefore, if pyramidal cells in the vicinity of the recording electrode do not cover the explored area homogeneously, this inhomogeneity will be reflected by the activity of their target interneuron(s).

It has been reported that timing of spikes within the theta cycle varies systematically as the rat traverses the place field of the recorded pyramidal cell (O'Keefe and Recce, 1993). This "phase precession" has important implications in the nature of neuronal coding (Jensen and Lisman, 1996; Skaggs et al., 1996; Tsodyks et al., 1996; Wallenstein and Hasselmo, 1997). The present findings suggest that phase advancement may not be unique to principal cells. Some interneurons, strongly coupled to their presynaptic pyramidal neuron, may undergo the same degree of theta phase precession as their master place cell. The implication of this prediction is that a subset of neurons can coherently "step out" from the population and form an assembly different in both discharge rate and timing from the remaining population.

\section{REFERENCES}

Abbott LF, Varela JA, Sen K, Nelson SB (1997) Synaptic depression and cortical gain control. Science 275:220-224.

Ali AB, Deuchars J, Pawelzik H, Thomson AM (1998) CA1 pyramidal to basket and bistratified cell EPSPs: dual intracellular recordings in rat hippocampal slices. J Physiol (Lond) 507:201-217.

Borst JG, Sakmann B (1999) Depletion of calcium in the synaptic cleft of a calyx-type synapse in the rat brainstem. J Physiol (Lond) 521:123-133.

Buzsáki G, Chrobak JJ (1995) Temporal structure in spatially organized neuronal ensembles: a role for interneuronal networks. Curr Opin Neurobiol 5:504-510.

Cobb SR, Buhl EH, Halasy K, Paulsen O, Somogyi P (1995) Synchronization of neuronal activity in hippocampus by individual GABAergic interneurons. Nature 378:75-78.

Cohen I, Miles R (2000) Contributions of intrinsic and synaptic activities to the generation of neuronal discharges in in vitro hippocampus. J Physiol (Lond) 2:485-502.

Csicsvari J, Hirase H, Czurkó A, Buzsáki G (1998) Reliability and state dependence of pyramidal cell-interneuron synapses in the hippocampus: an ensemble approach in the behaving rat. Neuron 21:179-189.

Czurkó A, Hirase H, Csicsvari J, Buzsáki G (1999) Sustained activation of hippocampal pyramidal cells by "space clamping" in a running wheel. Eur J Neurosci 11:344-352.

Frerking M, Schmitz D, Zhou Q, Johansen J, Nicoll RA (2001) Kainate receptors depress excitatory synaptic transmission at CA3 $\rightarrow$ CA1 synapses in the hippocampus via a direct presynaptic action. J Neurosci 21:2958-2966.

Freund TF, Buzsáki G (1996) Interneurons of the hippocampus. Hippocampus 6:347-470.

Fricker D, Miles R (2000) EPSP amplification and the precision of spike timing in hippocampal neurons. Neuron 28:559-569.

Galarreta M, Hestrin S (2001) Spike transmission and synchrony detection in networks of GABAergic interneurons. Science 292:2295-2299.

Geiger JR, Lubke J, Roth A, Frotscher M, Jonas P (1997) Submillisecond AMPA receptor-mediated signaling at a principal neuroninterneuron synapse. Neuron 18:1009-1023.

Gray CM, Maldonado PE, Wilson M, McNaughton B (1995) Tetrodes markedly improve the reliability and yield of multiple single-unit isolation from multi-unit recordings in cat striate cortex. J Neurosci Methods 63:43-54.

Gulyas AI, Miles R, Sik A, Toth K, Tamamaki N, Freund TF (1993)
Hippocampal pyramidal cells excite inhibitory neurons through a single release site. Nature 366:683-687.

Harris KD, Henze DA, Csicsvari J, Hirase H, Buzsáki G (2000) Accuracy of tetrode spike separation as determined by simultaneous intracellular and extracellular measurements. J Neurophysiol 84:401-414.

Henze DA, Borhegyi Z, Csicsvari J, Mamiya A, Harris KD, Buzsáki G (2000) Intracellular features predicted by extracellular recordings in the hippocampus in vivo. J Neurophysiol 84:390-400.

Hirase H, Leinekugel X, Czurkó A, Csicsvari J, Buzsáki G (2001a) Firing rates of hippocampal neurons are preserved during subsequent sleep episodes and modified by novel awake experience. Proc Natl Acad Sci USA 98:9386-9390.

Hirase H, Leinekugel X, Csicsvari J, Czurkó A, Buzsáki G (2001b) Behavior-dependent states of the hippocampal network affect functional topography of neurons. J Neurosci 21:RC145(1-4).

Jensen O, Lisman JE (1996) Hippocampal CA3 region predicts memory sequences: accounting for the phase precession of place cells. Learn Mem 3:279-287.

Kubie JL, Muller RU, Bostock E (1990) Spatial firing properties of hippocampal theta cells. J Neurosci 10:1110-1123.

Manor Y, Nadim F, Abbott LF, Marder E (1997) Temporal dynamics of graded synaptic transmission in the lobster stomatogastric ganglion. J Neurosci 17:5610-5621.

Markram H, Gupta A, Uziel A, Wang Y, Tsodyks M (1998) Information processing with frequency-dependent synaptic connections. Neurobiol Learn Mem 70:101-112.

McNaughton BL, Barnes CA, O'Keefe J (1983) The contributions of position, direction, and velocity to single unit activity in the hippocampus of freely-moving rats. Exp Brain Res 52:41-49.

Miles R (1990) Synaptic excitation of inhibitory cells by single CA3 hippocampal pyramidal cells of the guinea-pig in vitro. J Physiol (Lond) 428:61-77.

O'Keefe J, Nadel L (1978) The hippocampus as a cognitive map. Oxford: Clarendon.

O'Keefe J, Recce ML (1993) Phase relationship between hippocampal place units and the EEG theta rhythm. Hippocampus 3:317-330.

Redish AD, Battaglia FP, Chawla MK, Ekstrom AD, Gerrard JL, Lipa P, Rosenzweig ES, Worley PF, Guzowski JF, McNaughton BL, Barnes CA (2001) Independence of firing correlates of anatomically proximate hippocampal pyramidal cells. J Neurosci 21:RC134(1-6).

Sik A, Penttonen M, Ylinen A, Buzsáki G (1995) Hippocampal CA1 interneurons: an in vivo intracellular labeling study. J Neurosci 15:6651-6665.

Skaggs WE, McNaughton BL, Wilson MA, Barnes CA (1996) Theta phase precession in hippocampal neuronal populations and the compression of temporal sequences. Hippocampus 6:149-172.

Thomson AM, Bannister AP (1999) Release-independent depression at pyramidal inputs onto specific cell targets: dual recordings in slices of rat cortex. J Physiol (Lond) 519:57-70.

Tsodyks MV, Skaggs WE, Sejnowski TJ, McNaughton BL (1996) Population dynamics and theta rhythm phase precession of hippocampal place cell firing: a spiking neuron model. Hippocampus 6:271-280.

Tsodyks M, Uziel A, Markram H (2000) Synchrony generation in recurrent networks with frequency-dependent synapses. J Neurosci 20:RC50(1-5)

Waldeck RF, Pereda A, Faber DS (2000) Properties and plasticity of paired-pulse depression at a central synapse. J Neurosci 20:5312-5320.

Wallenstein GV, Hasselmo ME (1997) GABAergic modulation of hippocampal population activity: sequence learning, place field development, and the phase precession effect. J Neurophysiol 78:393-408.

Whittington MA, Traub RD, Jefferys JG (1995) Synchronized oscillations in interneuron networks driven by metabotropic glutamate receptor activation. Nature 373:612-615.

Wilson MA, McNaughton BL (1993) Dynamics of the hippocampal ensemble code for space. Science 261:1055-1058. 